\title{
CORROSÃO DE AÇO GALVANIZADO EM SOLUÇÕES ÁCIDAS
}

\section{CORROSION BEHAVIOR OF GALVANIZED STEEL IN ACID SOLUTIONS}

\author{
M. S. P. RUELA ${ }^{1}$, D. M. da SILVEIRA ${ }^{2}$ \\ ${ }^{1}$ Universidade Federal de São João del Rei, Departamento de Engenharia Química, Brasil \\ ${ }^{2}$ Universidade Federal de São João del Rei, Departamento de Engenharia Química, Brasil \\ E-mail:marcelaspruela@gmail.com
}

article info

Received 6 July 2016

Accepted 3 January 2017

Available online 6 January 2017
PAlAVRAS-CHAVE: Corrosão; Aço Galvanizado; Eletroquímica; Cloreto de Sódio; Sulfato de Sódio.

KEYWORDS: Corrosion; Galvanized Steel; Electrochemistry; Sodium Chloride; Sodium Sulfate.

RESUMO: Neste estudo, o comportamento corrosivo do aço galvanizado em soluções ácidas é analisado através dos ensaios de potencial de circuito aberto e polarização potenciodinâmica. Os corpos de prova foram imersos soluções de cloreto de sódio ( $\mathrm{NaCl}$ ) 3,5\% p/v e sulfato de sódio $\left(\mathrm{Na}_{2} \mathrm{SO}_{4}\right)$ 1\% p/v com pH iguais a 2 e 4 para ambas. $\mathrm{O}$ meio reacional mais propenso a corrosão foi de $\mathrm{NaCl} 3,5 \%$ e pH 4, enquanto os menos corrosivos foram soluções de $\mathrm{Na}_{2} \mathrm{SO}_{4}$, independentemente do $\mathrm{pH}$. Foi constatado que o fator que mais influenciou na corrosão foi a solução utilizada, sendo o pH pouco significante nas condições experimentais empregadas.

\begin{abstract}
In the present work, the corrosion behavior of galvanized steel is addressed by means of the open circuit potential and linear potentiodynamic polarization tests. The steel samples were immersed in sodium chloride $(\mathrm{NaCl}) 3.5 \% \mathrm{w} / \mathrm{v}$ and sodium sulfate $\left(\mathrm{Na}_{2} \mathrm{SO}_{4}\right) 1 \% \mathrm{w} / \mathrm{v}$ solutions with $\mathrm{pH}$ values of two and four. The solution of $\mathrm{NaCl} 3.5 \%$ and $\mathrm{pH} 4$ was the most susceptible to corrosion, while the least ones were $\mathrm{Na}_{2} \mathrm{SO}_{4}$ solutions, for any $\mathrm{pH}$ value. An analysis of the experimental results suggests that corrosion is mostly affected by solution's composition, whereas $\mathrm{pH}$ values have less significant effect.
\end{abstract}

\section{INTRODUÇÃO}

A corrosão é definida como a deterioração de um material por ação química ou eletroquímica do meio ambiente, aliada ou não a esforços mecânicos. Em geral, ela é um processo espontâneo que constantemente transforma os materiais metálicos, alterando sua durabilidade e seu desempenho, tornando-os insatisfatórios para os fins que se destinam. Ao estudar processos corrosivos, as variáveis dependentes do material metálico, do meio corrosivo e das condições operacionais devem ser levadas em consideração (GENTIL, 2011).

A fim de minimizar os danos causados pela corrosão do material, alguns métodos preventivos são adotados, sendo os revestimentos metálicos comumente empregados para a proteção do aço. Um exemplo de metal utilizado para essa finalidade é o zinco e o aço revestido com o zinco é chamado de aço galvanizado. Esse revestimento forma uma barreira 
física e proteção galvânica. A barreira física isola o aço em duas camadas durante diferentes etapas da corrosão. A primeira barreira é o zinco se revestindo, o que substitui sua função de isolamento pela formação de uma camada de produtos corroídos de zinco. Já a proteção galvânica significa que mesmo que uma parte do aço é exposta, a camada de zinco irá se corroer preferencialmente. Isso ocorre devido a diferença de potencial entre os potenciais de equilíbrio do zinco e do ferro, aproximadamente 350mV (SORIANO e ALFANTAZI, 2016; SANTOS et. al., 2015).

A corrosão do aço galvanizado pode ser descrita em três etapas:

1. O zinco sólido corrói, liberando íons $\mathrm{Zn}^{2+}$. Os produtos de corrosão do zinco, compostos de óxido, hidróxido ou sais básicos/neutros, formam uma camada aderente, porosa e de cor branca. A proteção galvânica ocorre nessa etapa, quando somente pequenas áreas do aço são expostas devido a imperfeições do revestimento. Em meio ácido, o produto de corrosão é formado principalmente por sais solúveis, como cloretos e sulfatos (SORIANO e ALFANTAZI, 2016; GENTIL, 2011).

2. A camada de produtos de corrosão cresce até o zinco ser empobrecido e uma camada fina, porosa e não protetiva ser formada. Durante essa etapa, a corrosão atinge a camada da liga $\mathrm{Zn}-\mathrm{Fe}$ e o potencial de corrosão muda para valores mais nobres.

3. A corrosão do aço se inicia e íons $\mathrm{Fe}^{2+}$ são liberados para o meio. Os produtos de corrosão do aço se tornam visíveis em forma de uma ferrugem vermelha (SORIANO e ALFANTAZI, 2016).

Com o propósito de avaliar o processo corrosivo do aço em soluções aquosas, que apresentam um mecanismo eletroquímico, diferentes técnicas eletroquímicas podem ser empregadas. O presente trabalho teve por objetivo avaliar o comportamento desse processo em chapas de aço galvanizado através das técnicas de potencial de circuito aberto e polarização potenciodinâmica linear, em soluções de cloreto de sódio e sulfato de sódio com concentração fixa e baixos valores de $\mathrm{pH}$.

\section{MATERIAIS E MÉTODOS}

\subsection{Materiais}

Com a intenção de desenvolver o estudo em questão, foram utilizados: soluções de cloreto de sódio $3,5 \% \mathrm{p} / \mathrm{v}$, sulfato de sódio anidro $1 \% \mathrm{p} / \mathrm{v}$, hidróxido de sódio $1 \mathrm{~mol} / \mathrm{L}$, ácido clorídrico $1 \mathrm{~mol} / \mathrm{L}$, chapas de aço galvanizado (composição da liga: 7,49\% Ti, 5,38\% Mn, $3,39 \% \mathrm{C}$ ), eletrodo de prata e eletrodo de platina.

\subsection{Preparo dos Ensaios}

Os ensaios foram realizados em uma célula eletroquímica com uma abertura lateral de $1 \mathrm{~cm}^{2}$ de área e três aberturas superiores. A chapa de aço galvanizado foi alocada na abertura lateral, o contra-eletrodo de platina foi colocado na primeira abertura superior, ao lado da chapa, e o eletrodo de referência de prata $(\mathrm{Ag} / \mathrm{AgCl})$ na segunda. Os ensaios foram avaliados 
primeiramente em soluções de cloreto de sódio $(\mathrm{NaCl})$ com concentração 3,5\% p/v e depois em soluções de sulfato de sódio $\left(\mathrm{Na}_{2} \mathrm{SO}_{4}\right)$ com concentração $1 \% \mathrm{p} / \mathrm{v}$ e pH iguais a 2 e 4 para as duas soluções. Para cada valor de $\mathrm{pH}$ foram feitas triplicatas a fim de garantir a reprodutibilidade dos resultados. $\mathrm{O} \mathrm{pH}$ inicial foi ajustado em alíquotas de aproximadamente $170 \mathrm{~mL}$, que é o volume de solução necessário para encher a célula eletroquímica, com $\mathrm{HCl}$ $1 \mathrm{M}$.

\subsection{Ensaios Eletroquímicos}

Para atingir o equilíbrio entre a amostra e o meio reacional, o ensaio de potencial de circuito aberto foi realizado. Para isso, foi utilizado o potenciostato Omnimetra PG-3906. O tempo do ensaio especificado foi de 3600 segundos e a amostragem foi 5000 milissegundos, resultando em um total de 720 amostras. O último valor de potencial obtido é denominado potencial de corrosão e esse é utilizado como referência no ensaio de polarização potenciodinâmica.

Ao terminar o ensaio de potencial de circuito aberto, o ensaio de polarização potenciodinâmica foi realizado. A taxa de varredura foi igual a $0,001670 \mathrm{~V} / \mathrm{s}$. Os limites de potenciais utilizados foram de $-0,3 \mathrm{~V}$ até $1,2 \mathrm{~V}$ para as soluções de $\mathrm{NaCl} 3,5 \%$ e $-1,0 \mathrm{~V}$ até $1,5 \mathrm{~V}$ para os ensaios com $\mathrm{Na}_{2} \mathrm{SO}_{4} 1 \%$, respeitando o valor de potencial de corrosão. Durante os dois testes, o pH foi medido de 15 em 15 minutos e ajustado quando necessário para manter o valor estabelecido inicialmente.

\section{RESULTADOS E DISCUSSÕES}

\subsection{Resultados dos Ensaios de Potencial de Circuito Aberto}

Nos ensaios de potencial de circuito aberto, o potencial de corrosão foi atingido no início do ensaio, ficando estáveis para ambos os valores de $\mathrm{pH}$ e ambas soluções, uma vez que a variação desse potencial foi menor do que $0,005 \mathrm{~V}$. Esse fato pode ser observado pelo gráfico gerado de potencial vs tempo, representado na Figura 1. Através desse gráfico observa-se que os valores obtidos para o potencial de corrosão foram próximos e que os potenciais adquiriram valores mais nobres para alcançar a estabilidade.

\subsection{Resultados dos Ensaios de Polarização Potenciodinâmica}

Soluções de cloreto de sódio: Nos ensaios de polarização potenciodinâmica linear, diferentes potenciais foram aplicados e registrados, assim como diferentes valores para a corrente. Em posse desses dados, foi possível gerar gráficos de $\log$ i vs E, viabilizando examinar o comportamento catódico e anódico nas curvas experimentais de polarização. A Figura 2 ilustra essas curvas para a solução de cloreto de sódio e seus respectivos valores de $\mathrm{pH}$, considerando apenas uma triplicata, visto que os resultados foram próximos.

Observando o gráfico, nota-se que as duas curvas estão bem próximas, indicando que o comportamento do aço galvanizado em soluções ácidas de $\mathrm{NaCl} 3,5 \%$ é similar e independente do valor de $\mathrm{pH}$. Além disso, pode-se ressaltar que o potencial de corrosão em pH 2 foi maior, sugerindo que esse meio foi mais resistente à corrosão do que em solução 
com pH 4. Vu et. al. (2013) reportou que em soluções ácidas nenhum óxido estável é formado.

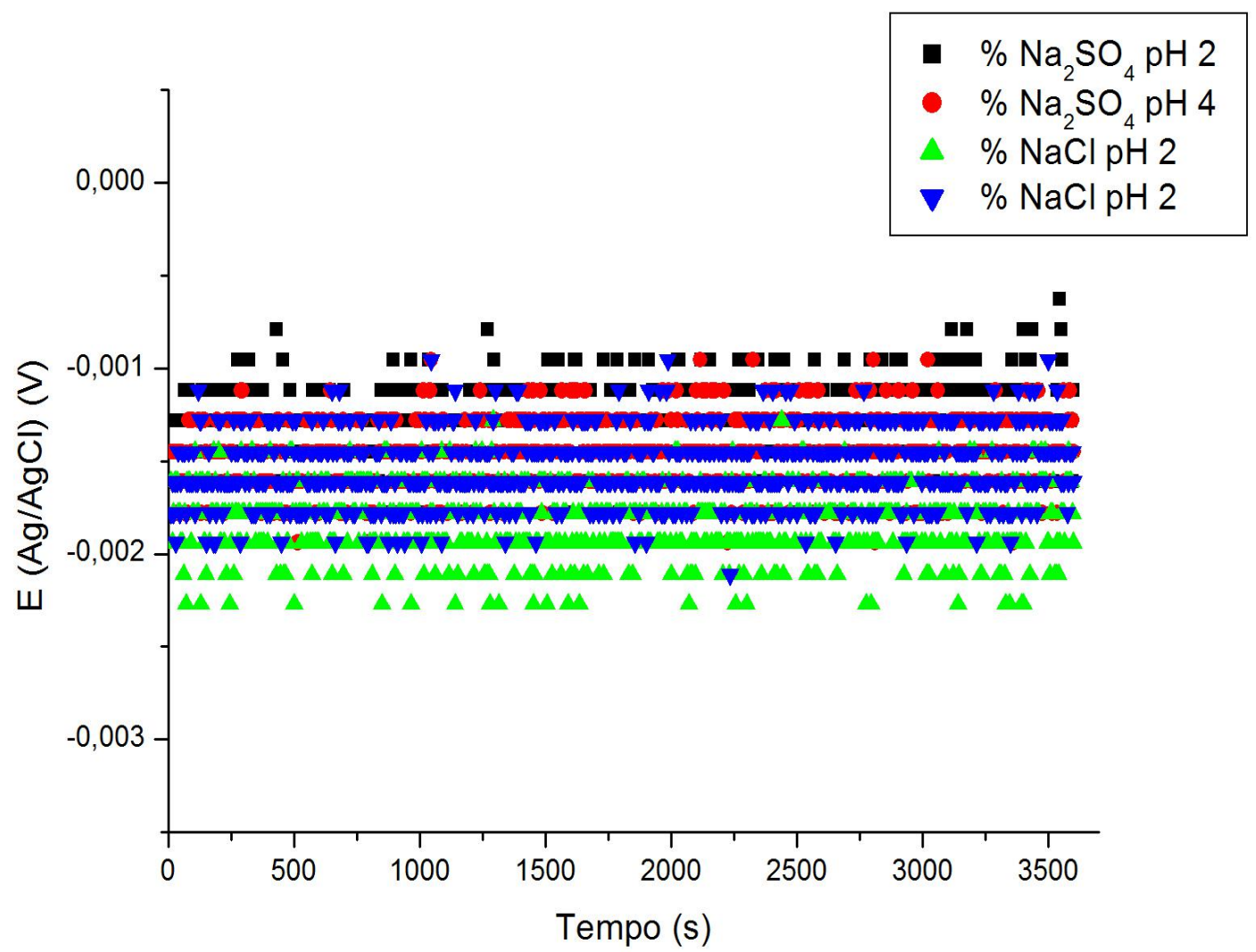

Figura 1 - Medidas de potencial de circuito aberto para cada triplicata.

Durante os ensaios isso pode ser notado através do aspecto da chapa de aço no final do experimento e a coloração castanho-alaranjada da solução eletrolítica. Ao retirar o eletrodo de trabalho do suporte, foi perceptível que houve a formação de ferrugem vermelha. Com isso, íons de $\mathrm{Fe}^{2+}$ foram liberados para a solução, formando hidróxido de ferro II, $\mathrm{Fe}(\mathrm{OH})_{2}$. Esse hidróxido sofre transformação de acordo com o teor de oxigênio presente. Nesse experimento o meio estava aerado, ocorrendo então a oxidação do $\mathrm{Fe}(\mathrm{OH})_{2}$, resultando em hidróxido de ferro III, $\mathrm{Fe}(\mathrm{OH})_{3}$, que possui coloração alaranjada típica. Essa característica foi ressaltada nos dois valores de $\mathrm{pH}$. Porém, quando o $\mathrm{pH}$ foi igual a 4 , a solução ficou com uma coloração mais forte e a chapa mais danificada. Isso pode ser explicado pelo grande volume de ácido clorídrico adicionado à solução para ajuste de $\mathrm{pH}$. Segundo Padilla e Alfantazi (2013), o íon cloreto age como um catalisador no processo de corrosão, aumentando a dissolução do zinco. $\mathrm{O}$ ideal seria usar solução de $\mathrm{H}_{2} \mathrm{SO}_{4}$ para ajustar o $\mathrm{pH}$, pois, dessa forma, a concentração de cloreto mantem consistente para todas as soluções (GENTIL, 2011; THOMAS et al., 2012).

Nas soluções com $\mathrm{pH} 4, \mathrm{o} \mathrm{pH}$ aumentou bastante durante todo o ensaio, chegando a valores entre 7 e 11 em um intervalo de 15 minutos. De acordo com Thomas et. al. (2012), o 
aumento de alcalinidade pode ser explicado devido a ocorrência da reação de redução de oxigênio, que resulta na liberação de íons $\mathrm{OH}^{-}$para o meio. Segundo Vu et. al. (2013), em um intervalo de $\mathrm{pH} 4$ a 11, essa reação de redução de oxigênio é a principal reação catódica para o zinco.

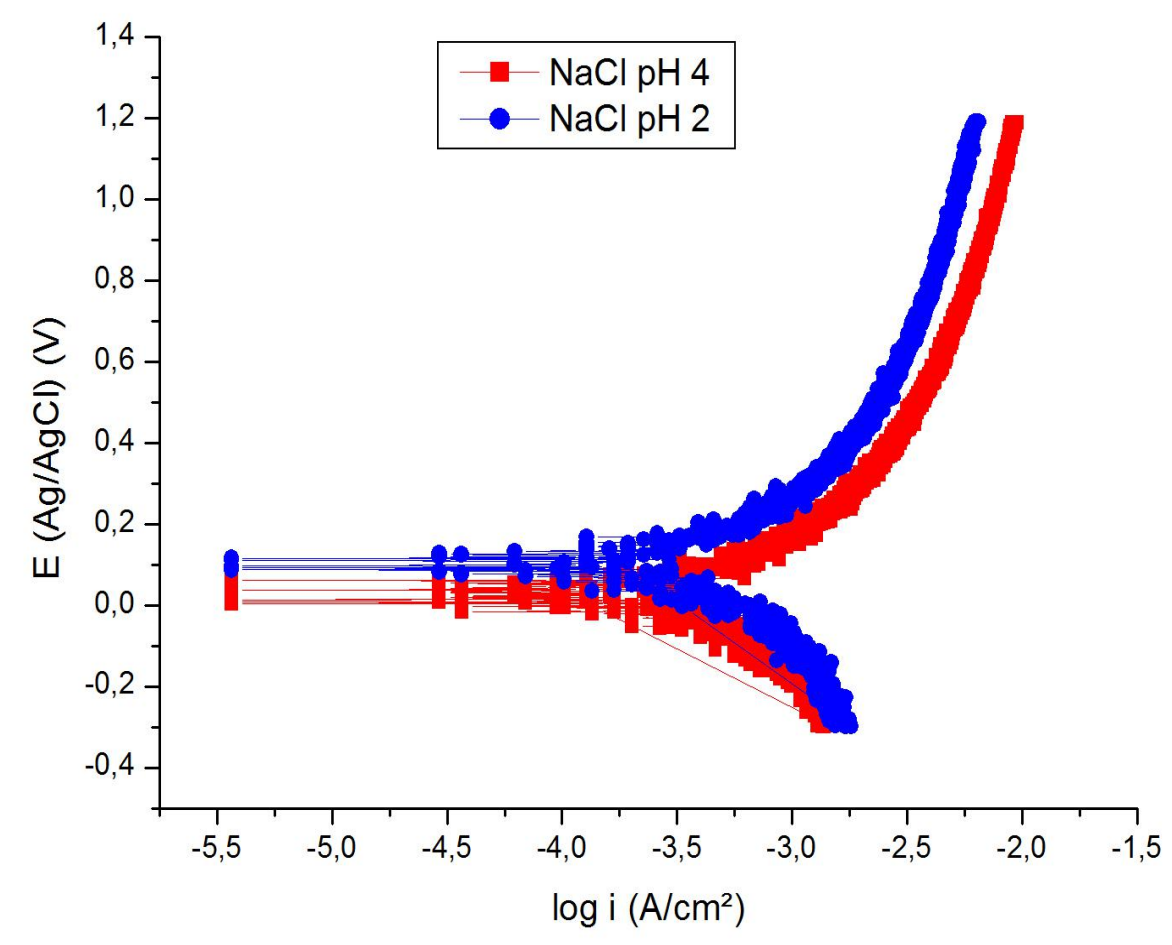

Figura 2 - Curvas de polarização experimental para os ensaios em $\mathrm{NaCl}$.

Soluções de sulfato de sódio: Da mesma forma que em solução de cloreto de sódio, os dados de potenciais e correntes foram registrados e a curva experimental de polarização gerada e ilustrada pela Figura 3.

Ao observar os gráficos, é possível notar um comportamento muito parecido para os dois ensaios, evidenciando que em soluções ácidas de $\mathrm{Na}_{2} \mathrm{SO}_{4} \quad 1 \%$ o comportamento corrosivo do aço galvanizado é similar, independentemente do valor do $\mathrm{pH}$.

Analisando a chapa após os ensaios, foi verificado que essa apresentou uma cor acinzentada e presença de um pó na área em que foi exposta. Geralmente, essa característica ocorre quando há a formação de um produto de corrosão sob a forma de pó branco, que não protege a superfície por ser antiaderente e poroso. Esse processo é conhecido como oxidação branca. Segundo Padilla e Alfantazi (2012), a presença de íons sulfato em baixos valores de pH acelera a corrosão e impede que o metal atinja a passividade (GENTIL, 2011).

\subsection{Comparação dos meios reacionais na influência da corrosão do aço galvanizado}


Com o propósito de comparar as diferentes soluções utilizadas nos ensaios, plotou-se o gráfico de uma triplicata para cada meio estudado no teste de polarização, exposto na Figura 4. Através desse gráfico, percebe-se que a solução de $\mathrm{Na}_{2} \mathrm{SO}_{4} 1 \%$ é mais resistente à corrosão do que a solução de $\mathrm{NaCl} 3,5 \%$. Isso pode ser observado por meio da curva de inflexão do gráfico, ou seja, no momento em que passa da região catódica para a anódica. Aquela curva que possui um valor de potencial mais nobre é a que apresenta um maior potencial de corrosão, e, consequentemente, uma maior resistência à corrosão. Em um estudo publicado por Padilla e Alfantazi (2012), em que foi avaliada a corrosão de uma mistura $\mathrm{NaCl} 3,5 \%$ e $\mathrm{Na}_{2} \mathrm{SO}_{4}$ com concentração variando de 1 a $4 \%$, constatou-se que um aumento na concentração de íons sulfato implica em um aumento na taxa de corrosão. Sendo assim, a solução de $\mathrm{Na}_{2} \mathrm{SO}_{4}$ pode ter apresentado uma maior resistência à corrosão devido a sua menor concentração.

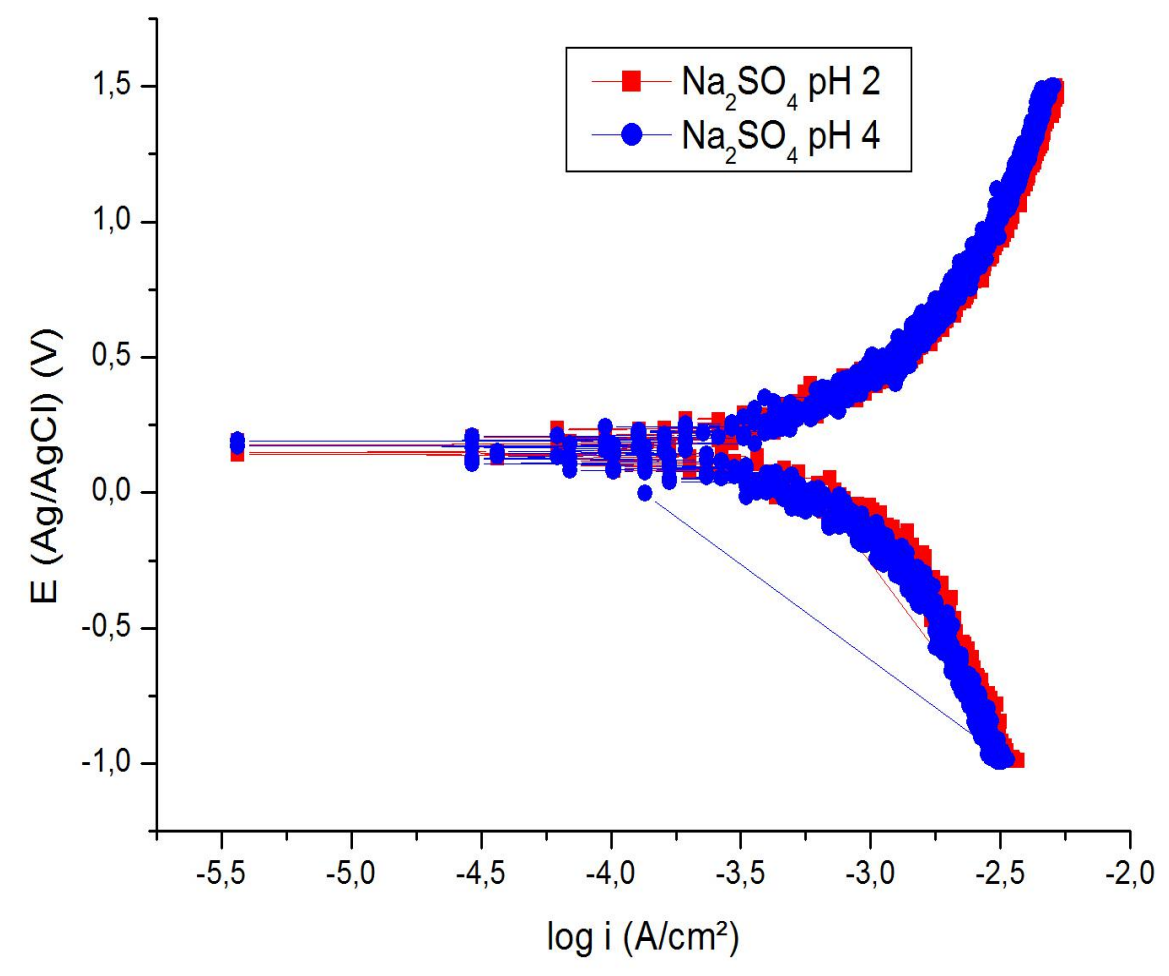

Figura 3 - Curvas de polarização experimental para os ensaios em $\mathrm{Na}_{2} \mathrm{SO}_{4}$.

É perceptível também que o comportamento entre uma mesma solução foi parecido, independente do $\mathrm{pH}$. Isso pode ser explicado pois, termodinamicamente, a espécie de zinco formada mais estável em um intervalo de $\mathrm{pH}$ de 1 até 5 é o íon $\mathrm{Zn}^{2+}$ (THOMAS et al., 2012). Uma vez que as espécies são iguais, espera-se que ocorra as mesmas reações de redução e oxidação no meio. Esse fato é facilmente visível ao analisar o diagrama de Pourbaix, exposto na Figura 5. Observa-se que, além de ambos formarem $\mathrm{Zn}^{2+}$, eles também encontram-se em uma região corrosiva, estando de acordo com os resultados previamente discutidos. 


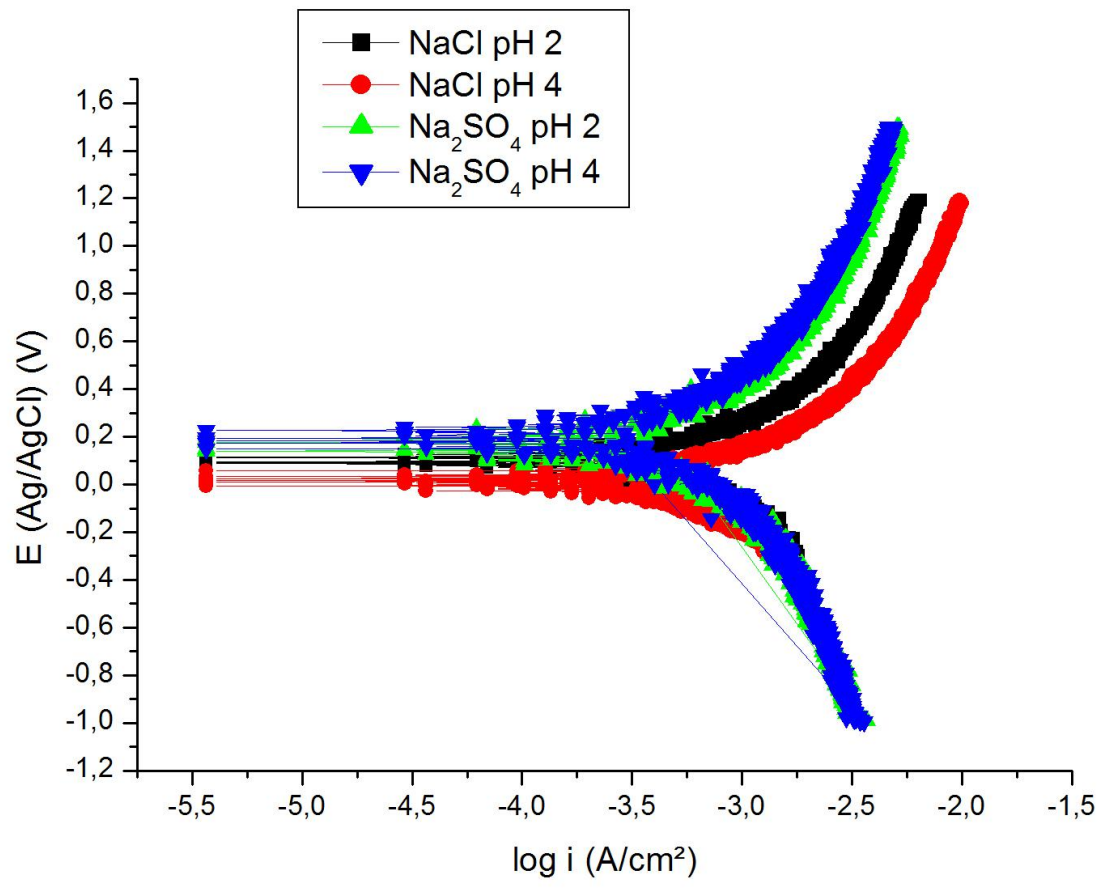

Figura 4 - Comparação do ensaio de polarização para cada meio reacional.

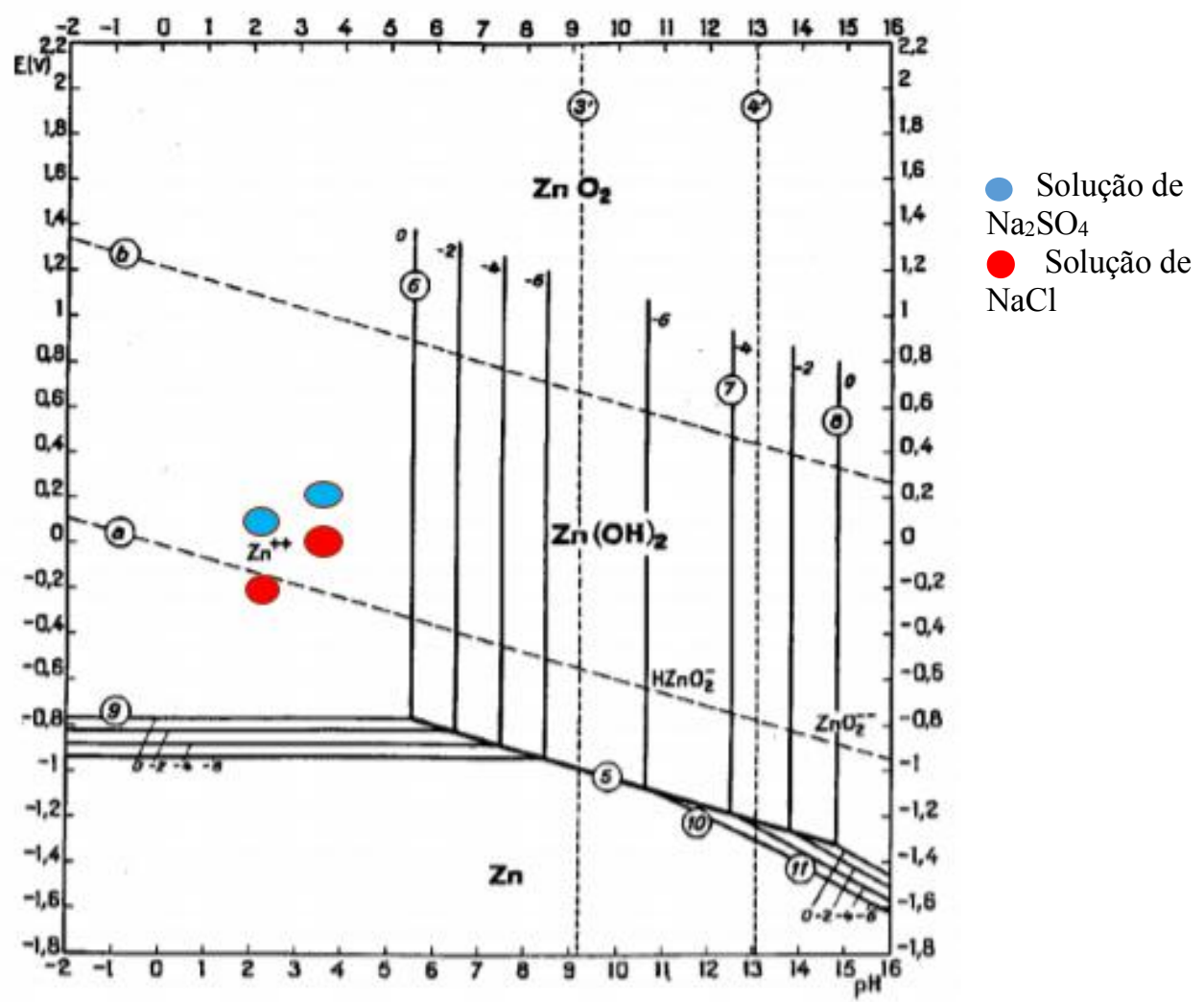

Figura 5 - Diagrama de Pourbaix para o sistema zinco-água a $25^{\circ} \mathrm{C}$ (POURBAIX, 1974). 


\subsection{Avaliação dos fatores que influenciaram na corrosão do aço galvanizado}

A fim de qualificar as principais condições que provocaram a corrosão da chapa de aço galvanizado, o gráfico de Pareto, ilustrado na Figura 6, foi gerado levando em consideração os meios corrosivos utilizados no ensaio de polarização. A solução eletrolítica, o pH e a interação entre ambos foram avaliados de acordo com os potenciais de corrosão registrados. Pelo gráfico, percebe-se que os argumentos apontados ao longo da discussão podem ser comprovados. A solução eletrolítica utilizada foi o fator que mais influenciou na corrosão, sendo a interação dessa solução com o pH do meio menos significante. Isso pode ser observado pela pouca diferença dos potenciais de corrosão entre o $\mathrm{pH} 2$ e 4 em todos os ensaios.

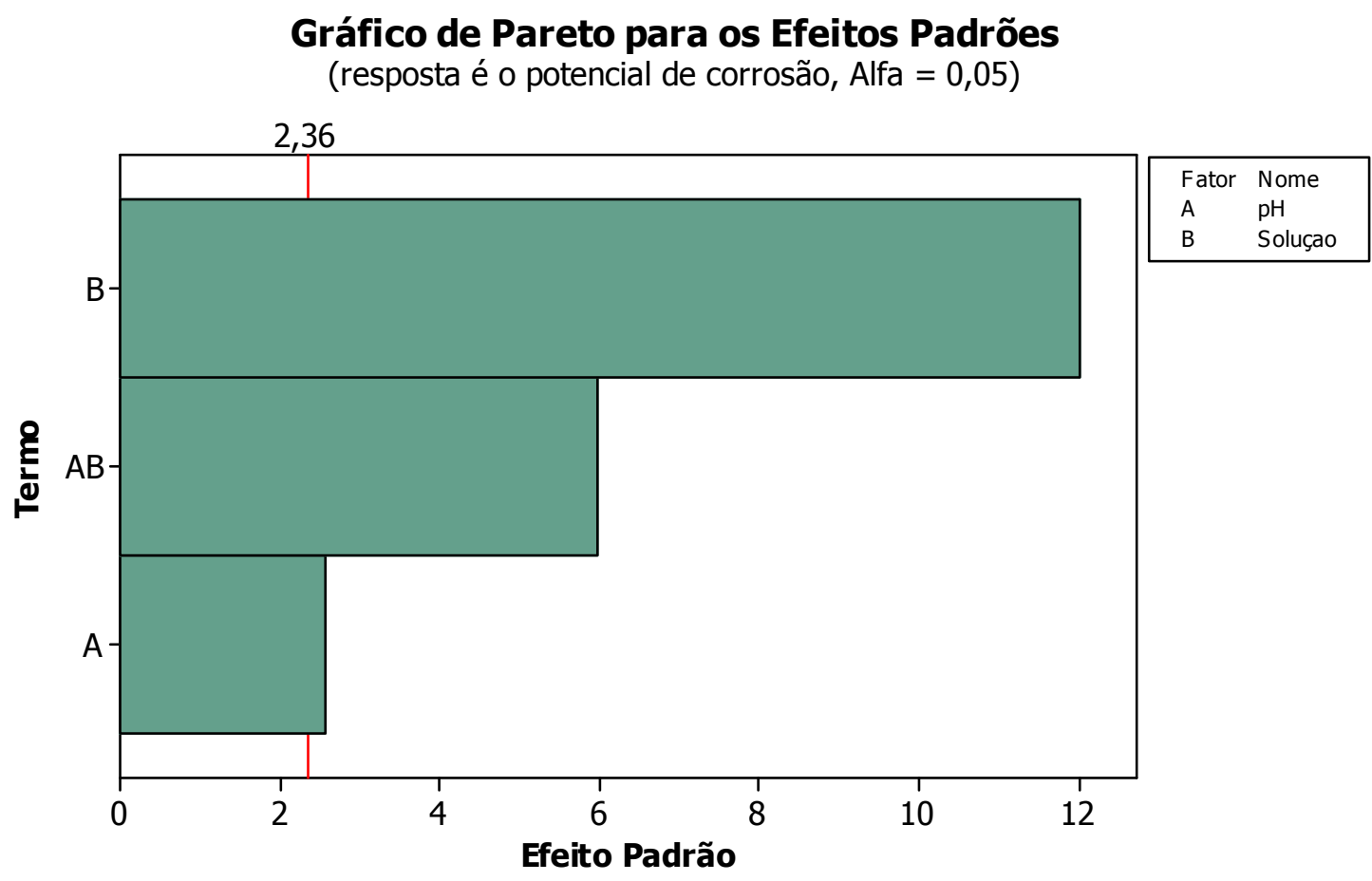

Figura 6 - Gráfico de Pareto dos efeitos do meio corrosivo.

\section{CONCLUSÃO}

De acordo com os resultados obtidos, o meio mais corrosivo para o aço galvanizado é $\mathrm{NaCl} 3,5 \%$ e pH 4, pois esse apresentou uma maior concentração de íons cloreto em solução. Para os outros ambientes testados, o comportamento corrosivo da chapa de aço galvanizado foi parecido, sendo a solução de $\mathrm{Na}_{2} \mathrm{SO}_{4} \quad 1 \%$ a menos agressiva. A condição que mais influenciou nos ensaios foi a solução utilizada, os íons sulfato foram considerados menos hostis do que os íons cloreto provavelmente devido a sua menor concentração presente em solução. A solução ácida foi considerada uma condição pouco significante na avaliação do comportamento da corrosão em aço galvanizado. 


\section{REFERÊNCIAS}

GENTIL, V. Corrosão, 6 ed, Rio de Janeiro: LTC, 2011. 360 p.

PADILLA, V.; ALFANTAZI, A. Effects of Oxygen and Sulfate Concentrations on the Corrosion Behavior of Zinc in $\mathrm{NaCl}$ Solutions. Corrosion Science. v. 68, 2012.

PADILlA, V.; ALFANTAZI, A. Corrosion Performance of Galvanized Steel in Na2SO4 and $\mathrm{NaCl}$ Solutions at Subfreezing Temperatures. Corrosion Science. v. 69, p. 174$185,2013$.

POURBAIX, M. Atlas of electrochemical equilibria in aqueous solutions, 2 ed. Houston: NACE, 1974.

SANTOS, A. P.; MANHABOSCO, S. M.; RODRIGUES, J. S.; DICK, L. F. P. Comparative study of the corrosion behavior of galvanized, galvannealed and $\mathrm{Zn} 55 \mathrm{Al}$ coated interstitial free steels. Surface and coatings technology. v. 279, p.150-160, 2015.

SORIANO, C.; ALFANTAZI, A. Corrosion behavior of galvanized steel due to typical soil organics. Construciton and building materials. v. 102, p. 904-912, 2015.

THOMAS, S.; BIRBILIS, N.; VENKATRAMAN, M. S.; COLE, I.S. Corrosion of Zinc as o Function of pH. Corrosion Science. v. 68, 2012.

VU, T.N.; VOLOVITCH, P.; OGLE, K. The effect of $\mathrm{pH}$ on the selective dissolution of $\mathrm{Zn}$ and Al from Zn-Al coatings on steel. Corrosion Science. v. 67, p.42-49, 2013. 